\title{
Comparative expression analysis of inflammatory and immune-related genes in cattle during acute infection with foot-and-mouth disease virus in Egypt
}

\author{
Abeer F. El Nahas ${ }^{1 凶}$, Walaa S.H. Abd El Naby ${ }^{1}$, Shymaa A. Khatab ${ }^{1}$, \\ Al-Zahraa A. Fergany ${ }^{1}$, Rashed R. Rashed ${ }^{2}$ \\ ${ }^{1}$ Genetics Laboratory, ${ }^{2}$ Animal Behavior, Animal Husbandry and Animal Wealth Development Department, \\ Faculty of Veterinary Medicine, Alexandria University, Egypt \\ abeer.elnahas@alexu.edu.eg
}

Received: July 14, 2020 Accepted: December 29, 2020

\begin{abstract}
Introduction: Foot-and-mouth disease is a highly infectious viral disease affecting all cloven-footed domestic animals. The three foot-and-mouth disease virus (FMDV) serotypes A, O and SAT2 are at present the greatest threat to susceptible animals in Egypt. The aim of the present study was, for the host factors associated with different FMDV infections in cattle during the acute phase, to compare these factors' influence on the expression of the IL-10,TLR-2, TNF- $\alpha, C X C L 10, C D 48, N F A T C 4$ and IFNG inflammatory and immune-related genes. Materials and methods: Vesicular fluid and epithelium samples were obtained from at least three infected cattle on the same affected farm during three different FMDV outbreaks and were used for serotyping of the virus and for expression analysis of host genes. A two-step RT-PCR was used for diagnosis of the virus with primers specific for each serotype. Results: In quantitative PCR analysis, the expression patterns of TLR-2 and IFNG were prominent, while NFATC4 expression was absent in all FMDV-infected cattle. The highest expression of $C D 48$ was associated with increased expression of other inflammatory and immune-related genes $(I L-10, T L R-2, T N F-\alpha$ and $I F N G)$, which may be an indication of rapid virus clearance. Conclusion: The use of vesicular fluid and epithelium for investigation of viral and immune-related gene expression levels in acute FMDV infection is possible. Host-dependent variation in the expression of the studied genes was observed in different FMDV serotype outbreaks.
\end{abstract}

Keywords: FMDV, gene expression, cattle, immune-related genes, serotype.

\section{Introduction}

Foot-and-mouth disease (FMD) is a highly infectious cross-border disease that affects domestic and wild cloven-hoofed animal species; its occurrence has inflicted economic losses multiple times (15). The effect of the disease differs considerably between endemic and non-endemic and developed and developing countries $(2,22)$.

Foot-and-mouth disease is caused by a small, nonenveloped, single-stranded RNA virus belonging to the Picornaviridae family and Aphthovirus genus. Three strains of the FMD virus (A, O and SAT2) are the causes of the disease circulating in Egypt (5). It has seven known distinct worldwide serotypes (A, O, C, Asia 1 and South African Territories (SAT1-3)) $(13,17,18)$. FMD outbreaks occur by contact with infected animals, mechanically by contaminated agents from infected farms or through airborne transmission by wind carrying the virus even from thousands of kilometers away $(6,21)$.

Natural immunity plays an essential role in virus circulation among animals and explains the inability of some animals to clear the virus among them $(8,9)$. Footand-mouth disease virus (FMDV) corrupts the early immune response through its effects on innate immune mechanisms (8). It causes inhibition of secretion of antigen-presenting cells and their precursors through impairing cytokine-driven pathways, promotes viral replication and delays the adaptive $\mathrm{T}$ cell response (9), and consequently degrades immune function. Infection with one of the seven FMDV serotypes does not confer 
immunity to other serotypes or to divergent strains within that serotype $(7,8)$. However, an animal which survives is still immune to the first serotype for an ample period of time. Additionally, repeated infections with other FMD serotypes may arouse moderate clinical responses or grant some protection $(7,8)$.

Foot-and-mouth disease viral RNA levels, tissuespecific distribution and local cytokine expression vary $(14,19)$. Stenfeldt et al. (25) microscopically determined the localisation of FMD virus in the basal epithelial layers of the dorsal soft palate (DSP) and pharynx. Basically, as the ideal sample type, epithelium or vesicular fluid is used for laboratory diagnosis of the virus and is collected from intact or recently ruptured vesicles on the tongue, buccal mucosa or feet (31).

To address the lack of data on the host response induced in FMD outbreaks with distinct serotypes as their aetiological agents, the principle aim of the present study was to compare the host factors associated with different FMDV infections through the assessment of the differences in the expression of some inflammatory and immune-related genes (IL-10, TLR-2, TNF- $\alpha$, CXCL10, CD48, NFATC4 and IFNG) in cattle during the acute phase of FMD infection. Also, the study proposes to gauge the benefits of the use of vesicular fluid and tissue for diagnosis of the virus and for assessment of the expression of immune-related gene expression in the infected cattle.

\section{Material and Methods}

Sample collection. The samples were collected from clinically infected cattle from private farms in Behera and Kafer El Sheikh governorates during three different outbreaks in February 2017, November 2017, and February 2018 (two different farms). Vesicular fluid and epithelium samples were collected from the buccal mucosa and tongue of the infected cattle. To reduce animal suffering, sample collection took place only once and the sample served for both virus isolation and host gene expression assessment. The area over the vesicles was washed with phosphate buffered saline (PBS), and the samples were mixed with equal amounts of glycerol, $0.04 \mathrm{M}$ phosphate buffer ( $\mathrm{pH} 7.2-7.6)$, and antibiotic mixture (penicillin-streptomycin $\left.\left(10,000 \mathrm{U} / \mathrm{mL}-\mathrm{Gibco}^{\mathrm{TM}}\right)\right)$ in sterile screw-capped tubes. The samples were marked with the date of collection, sex, and age of the animal and were kept, transported and submitted to the laboratory in an ice box and stored at $-80^{\circ} \mathrm{C}$ until RNA isolation. Sampling was carried out following the procedures described by the OIE (31). All procedures and experiments were accepted by the local animal use ethics committee of the Faculty of Veterinary Medicine, the Alexandria University Institutional Animal Care and Use Committee.

Table 1: Serotype-specific primer sequences for FMD virus detection

\begin{tabular}{llcc}
\hline Primer & \multicolumn{1}{c}{$\begin{array}{c}\text { Sequence } \\
5^{\prime}-3^{\prime}\end{array}$} & $\begin{array}{c}\text { Amplicon size } \\
(\mathrm{bp})\end{array}$ & $\begin{array}{c}\text { Annealing temp } \\
\left({ }^{\circ} \mathrm{C}\right)\end{array}$ \\
\hline $\begin{array}{l}\text { Universal FMD } \\
\text { primer }\end{array}$ & $\begin{array}{l}\text { F - CCTACCTCCTTCAACTACGG } \\
\text { R - GAAGGGCCCAGGGTTGGACTC }\end{array}$ & 216 & 48 \\
Serotype O & F - AGCTTGTACCAGGGTTTGGC & & 46 \\
Serotype SAT2 & R - GCTGCCTACCTCCTTCAA & 633 & 50 \\
& R - TGGGACACMGGIYTGAACTC & & \\
Serotype A & F - TACCAAATTACACACGGGAA & 1145 & 55 \\
& R - GACATGTCCTCCTGCATCTG & $863-866$ & \\
\hline
\end{tabular}

Table 2: Cattle primer sequences for gene expression

\begin{tabular}{|c|c|c|c|}
\hline Primer & $\begin{array}{l}\text { Sequence } \\
5^{\prime}-3^{\prime}\end{array}$ & $\begin{array}{l}\text { Amplicon size } \\
\text { (bp) }\end{array}$ & $\begin{array}{l}\text { Annealing temp } \\
\qquad\left({ }^{\circ} \mathrm{C}\right)\end{array}$ \\
\hline CXCL10 & $\begin{array}{l}\text { F - AGTGGAAGCCCCTGCAGTAAA } \\
\text { R - AGTCCCAGCCTTGCTACTGACA }\end{array}$ & 117 & 56 \\
\hline$I L-10$ & $\begin{array}{l}\text { F - CCAAGCCTTGTCGGAAATGA } \\
\text { R - GTTCACGTGCTCCTTGATGTCA }\end{array}$ & 94 & 60 \\
\hline$I F N G$ & $\begin{array}{l}\text { F - TCTTCTCAAGCCTCAAGTAACAAGT } \\
\text { R - CCATGAGGGCATTGGCATAC }\end{array}$ & 103 & 56 \\
\hline$H P R T$ & $\begin{array}{l}\text { F - GCCGACCTGTTGGATTACAT } \\
\text { R - ACACTTCGAGGGGTCCTTTT }\end{array}$ & 289 & 56 \\
\hline$T L R-2$ & $\begin{array}{l}\text { F - CCATTGACAAGAAGGCCAT } \\
\text { R - AACCCTTCCTGCTGAGTCTCAT }\end{array}$ & 107 & 56 \\
\hline NFATC4 & $\begin{array}{l}\text { F - AACCACTGCCCCTCTCTGAAAC } \\
\text { R - CCTCGACCCCAGATCACAAAGA }\end{array}$ & 107 & 56 \\
\hline
\end{tabular}


Isolation and detection of foot-and-mouth virus RNA. RNA was extracted from the vesicular fluid and epithelium using a QiAmp Viral RNA Mini Kit (Qiagen, Hilden, Germany) according to the manufacturer's instructions. The isolated RNA was immediately used in a reverse transcription (RT) reaction for synthesis of cDNA, using a SensiFAST ${ }^{\text {TM }}$ cDNA Synthesis Kit (Bioline, London, UK) following the manufacturer's instructions. The reaction mixture consisted of $5 \mu \mathrm{L}$ of isolated RNA, $4 \mu \mathrm{L}$ of $5 \mathrm{X}$ RT buffer, $1 \mu \mathrm{L}$ of reverse transcriptase and RNase/DNase free water to make a final volume of $20 \mu \mathrm{L}$. The thermal cycler program was carried out at $25^{\circ} \mathrm{C}$ for $10 \mathrm{~min}, 42^{\circ} \mathrm{C}$ for $15 \mathrm{~min}$ and $4^{\circ} \mathrm{C}$ as the holding temperature. A conventional PCR was used to amplify cDNA corresponding to the VP1 gene with FMDV universal primer and serotype-specific primers as shown in Table 1. The amplified PCR products were electrophorosed on $1.5 \%$ agarose gel, and the bands were visualised and photographed on a UV transilluminator (InGenius gel documentation system, Syngene, Cambridge, UK).

Host RNA isolation and cDNA synthesis. Extracted RNA from the previous step was also used for synthesis of cDNA for assessment of the host immunerelated genes by using the SensiFASTTM cDNA Synthesis Kit as described in the previous step with a $3 \mu \mathrm{L}$ aliquot of the RNA. The host cDNA was verified by Bos taurus hypoxanthine phosphoribosyl transferase 1 (HPRT1) as a cattle housekeeping gene and then stored at $-20^{\circ} \mathrm{C}$ until further use.

Expression analysis of selected genes in FMDinfected cattle using quantitative real-time PCR. A quantitative real-time PCR was carried out to reveal the expression profiles of the $I L-10, T L R-2, T N F-\alpha$, CXCL10, CD48, NFATC4, and IFNG inflammatory and immune-related genes using Sensi-FAST ${ }^{\mathrm{TM}}$ SYBR green with low ROX (Bioline) according to the manufacturer's instructions. The thermal program was set as an initial denaturation $\left(95^{\circ} \mathrm{C}\right.$ for $\left.10 \mathrm{~min}\right)$ followed by 40 cycles of $95^{\circ} \mathrm{C}$ for $15 \mathrm{~s}$ and the annealing temperatures shown in Table 2 for $15 \mathrm{~s}$. The levels of mRNA were normalised against the amount of HPRT1 mRNA (endogenous control), and the relative level was determined by the comparative threshold cycle $2^{\wedge(-\Delta \Delta \mathrm{ct})}$ method (23). Three calves of approximately three months of age (non-vaccinated and uninfected) were used as a control (normaliser).

Statistical analysis. Statistical analysis was done using GraphPad Prism software version 6 (GraphPad Software, San Diego, CA, USA). One-way analysis of variance (ANOVA) was used for comparison of each gene expression level with the control level. The results were obtained as fold change mean \pm standard deviation, and the significance level was set at a probability value of $\mathrm{p}<0.05$.

\section{Results}

FMDV serotype determination in the infected cattle. Conventional PCRs were performed to determine the FMDV serotypes following a confirmatory PCR using a universal FMDV primer to confirm infection. The PCR generated a single band corresponding to the expected size for the universal FMDV primer (216 bp) (Fig. 1A). With serotype-specific primers, amplification was successful for serotype $\mathrm{O}$ twice in February and November 2017 with an amplicon size of $633 \mathrm{bp}$, and for serotype SAT2 on two different farms in February 2018 with an amplicon size of 1145 bp (Fig. 1B and C). Serotype A was not detected in any studied sample.

Expression of selected inflammatory and immune-related genes. Initially, the quality of cattle cDNA from the vesicular epithelium was verified and the cDNA was successfully amplified using the HPRT gene as a cattle housekeeping gene (Fig. 1D). Variations in the expression level of the selected genes in the infected cattle were reported. The most commonly expressed genes in all outbreaks were $T L R-2$ and $I F N G$, followed by $C D 48$ and $T N F-\alpha$. Expression of the $T N F-\alpha$ gene was most abundant in the cattle infected with O serotype 2 (Fig. 2B) and SAT2 serotype 2 (Fig. 3A). CD48 expression was strongest in O serotype 2 (Fig. 2B) and SAT2 serotype 2 (Fig. 3A) infections. Additionally, the $I L-10$ gene showed increased expression in the same serotype infections along with SAT2 serotype 1 (Fig. 2B), however, its expression was downregulated in O serotype 1 (Fig. 2A).
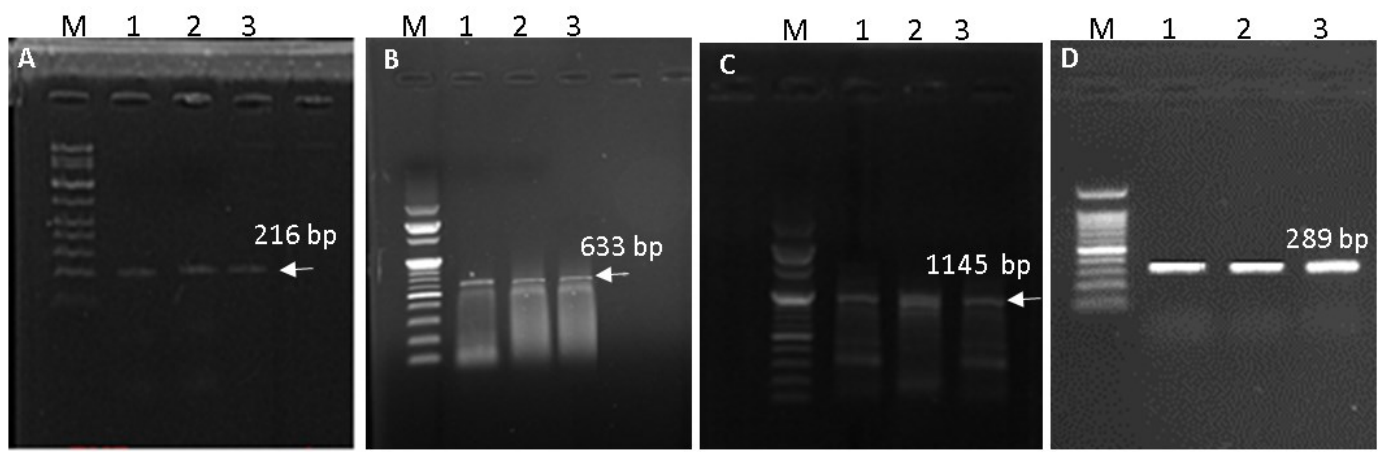

Fig. 1. Electrophoresis of PCR product of FMD virus. A: FMDV universal primer; B: O serotype; C: SAT2 serotype in clinically infected cattle; D: PCR product of bovine HPRT1 from vesicular fluid; M - DNA Ladder (1.5 Kb); lanes 1-3 - PCR products 
A

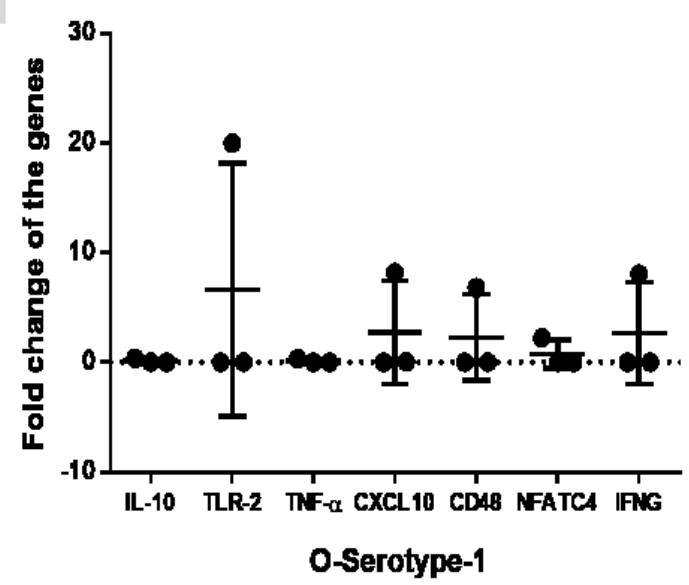

B

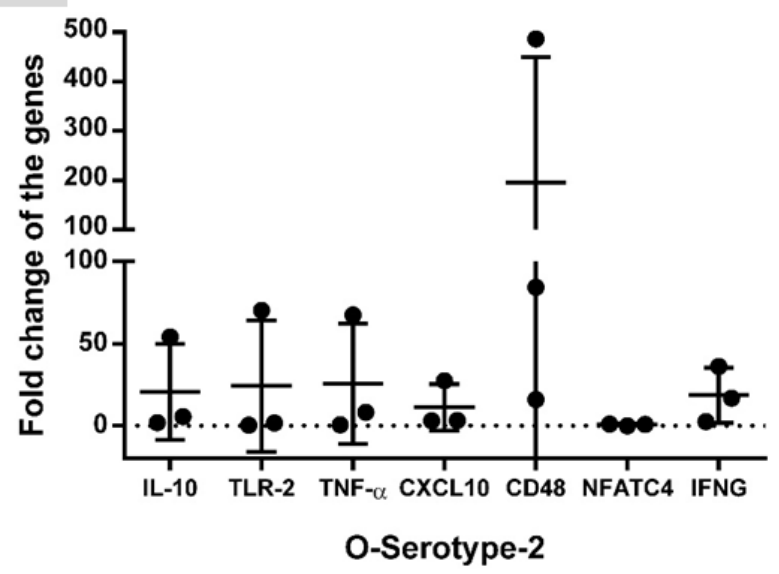

Fig. 2. The relative expression level of some inflammatory and immune-related genes in cattle infected with FMD virus (O serotype) in two different serotypes: O serotype 1 in February 2017 and O serotype 2 in November 2107. The fold change of the expressed genes was calculated relative to the control group (non-vaccinated and uninfected). The fold change for the control group was 1
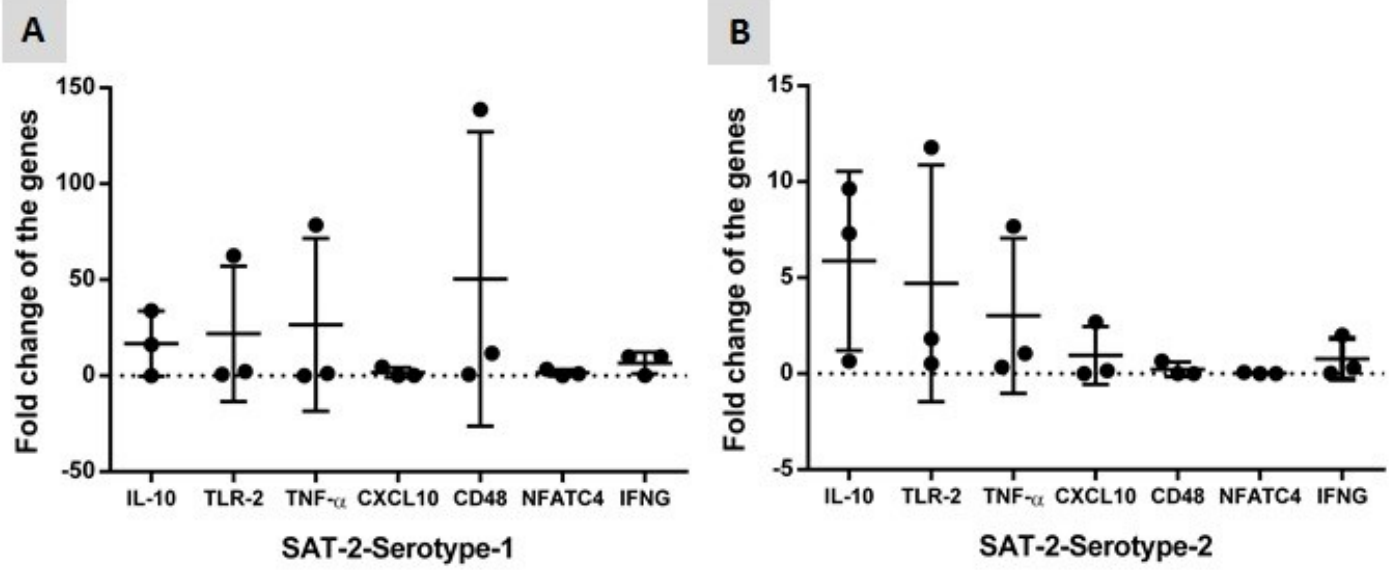

Fig. 3. Relative expression levels of some inflammatory and immune-related genes in-cattle infected with FMD virus (SAT-2 -serotype) serotypes 1 and 2, representing two different farms. The fold change of the expressed genes was calculated relative to the control group (non-vaccinated and uninfected). The fold change for the control group was 1

Levels of $I L-10, T N F-\alpha$, and NFATC4 tended to decrease compared to the control level $(=1)$ in $\mathrm{O}$ serotype 1-positive cattle samples (Fig. 2A), while those positive for SAT2 serotype 1 showed a decrease in CXCL10 and NFATC4 relative to the control level (Fig. 3A).

\section{Discussion}

Several studies reported different tissue distribution of FMD virus during acute and persistent infection (3, 19). In our study, we reported strong expression of the HPRT1 cattle housekeeping gene (Fig. 1D) in the vesicular fluid and vesicular epithelium of acutely infected cattle.

Toll-like receptors (TLRs) are conserved immune cell-surface receptors which are instrumental in pathogen recognition and innate immune stimulation. They recognise preserved molecules known as pathogen-associated molecular patterns, which derive from microorganisms (11). The expression pattern of TLR-2 in the samples from outbreak cattle with any of the FMDV serotypes in our study is high because recognition of the virus by TLRs initiates signal transduction pathways, which stimulates the expression of genes that control innate immune responses (27).

IL-10 is an anti-inflammatory cytokine; it can modulate immune processes and inhibit cellular responses via a variety of mechanisms. Zhang et al. (33) compared levels of IL-10 between FMD outbreak herdmates and found very low and elevated amounts. They correlated elevated IL-10 at the beginning of infection with FMDV with carrier status and little IL-10 at the same stage with non-carrier status. The expression profiles of IL-10 in our data differed by infecting serotype: the animals infected with FMDV O serotype 2 and SAT2 serotypes and 2 had higher levels of IL-10 expression as they may be infection carriers.

The $C D 48$ gene is a member of the $C D 2$ subfamily of the immunoglobulin superfamily which produces a protein known as B-lymphocyte activation marker. It 
is found on the surface of lymphocytes and other immune cells and participates in the activation and differentiation pathways in these cells, being the first B-cell specific cellular differentiation antigen $(28,32)$. We demonstrated that CD48 gene expression was increased in sample isolates collected during different FMDV serotypes infection with different levels of upregulation ranging from 195.61 to 50.42-fold for O serotype 1 and SAT2 serotype 1, and its expression varied from 0.22 to 2.28 in other two outbreaks (O serotype 2, and SAT2 serotype 2). Tissot et al. (29) suggested that increased $C D 48$ expression occurs under inflammatory conditions, and that exposure to IFN- $\alpha$, IFN- $\beta$ and IFN- $\gamma$ cytokines can increase its expression in peripheral blood mononuclear cells. Similarly we demonstrated that the highest CD48 accompanied O serotype 2 and SAT 2 serotype 1 infection. When they were the infectious agents, both serotypes also coincided with a higher level of TNF- $\alpha$ expression.

Tumour necrosis factor alpha is an important proinflammatory cytokine that simultaneously is produced by the immune response and plays a major role in its regulation, being also an actor in host defense mechanisms. We also detected its high level when O serotype 2 and SAT2 serotypes 1 and 2 were the aetiological agents. Biswal et al. (4) demonstrated genetic and antigenic variation of foot-and-mouth disease virus which was reflected by different inflammatory and immune responses of infected cattle.

Haagmans and Osterhaus (10) proposed a role for CXCL10 during virus infection wherein it is important for natural killer cell recruitment to limit viral replication during virus infection, and noted that the levels of CXCL10 in the early phase of the infection correlate with viral titre. The levels of expression in our study are 2.74-, 11.25-, 1.67-, and 0.96-fold for the acute phase of the studied outbreaks. The highest level of this gene (11.25-fold), which occurred in O serotype 2 infection, was also associated with the highest expression of $C D 48$ (195.61-fold) and the $I L-10, T L R-2, T N F-\alpha$ and $I F N G$ inflammatory and immune-related genes, which may be an indication of rapid clearance of the viral infection (16).

The NFATC4 gene codes for the nuclear factor of activated $\mathrm{T}$ cells (NFAT) protein. The protein has an important role in the expression of $I L-2$ or $I L-4$ cytokine genes in $\mathrm{T}$ cells. It could also regulate the activation, proliferation and the differentiation of the programmed death of T-lymphocytes (20). However, Razvi and Welsh (24) demonstrated that T lymphocyte programmed cell death during acute viral infection is a causal agent of virus-induced immune deficiency; therefore, the low expression of the NFATC4 gene in all the sample isolates from the studied outbreaks of FMD indicates the active immune status of the animals to different FMD outbreaks during acute infection.

$I F N G$ has an essential role in immune response to viral infection through enhancing macrophage activity and stimulating adaptive cell-mediated immunity (26). We demonstrated an increased level of IFNG in the different FMD outbreaks in our study. Similarly, Van Wyk et al. (31) reported increased expression of $I F N G$ in animals during acute bovine viral diarrhoea virus infection. Additionally, Kang et al. (12) reviewed the direct antiviral mechanisms of IFNG and stated that it inhibits the entry of the virus during its invasion of the cytoplasm from the endosome. Furthermore, IFNG inhibits the acute infection of BK virus efficiently irrespective of the viral strain (1).

Stenfeldt et al. (25) demonstrated a significant difference in the host response in cytokine mRNA expression in pharyngeal epithelial samples from FMDV-infected cattle, although they detected downregulation of $I F N-\beta$ mRNA and upregulation of IFN- $\alpha$ mRNA, which is the opposite of our results. This may be attributed to different tissues used or different FMDV serotypes as aetiological agents.

We conclude that the possibility exists of using vesicular fluid and epithelium for both diagnosis of the virus's presence and estimation of immune-related gene expression in acute FMDV infection. It can also be stated that host differences in the expression of these genes are prominent with serotype-disparate FMDV infections. The expression of TLR-2 and IFNG is potentiated and the expression of NFATC4 is curtailed in all FMDV-infected animals irrespective of serotype. The highest expression of CD48 is associated with increased expression of the other inflammatory and immune related genes $I L-10, T L R-2, T N F-\alpha$ and $I F N G$, which may be an indication of rapid clearance of the viral infection.

Conflict of Interests Statement: The authors declare that there is no conflict of interests regarding the publication of this article.

Financial Disclosure Statement: The source of funding of the research and the article was the Egyptian Academy of Science (JESOR 2015 cycle 3, Project ID 119: strategic control of endemic foot-and-mouth disease in Egypt).

Animal Rights Statement: All procedures and experiments were accepted by the Alexandria University Institutional Animal Care and Use Committee as the local ethics committee for the Faculty of Veterinary Medicine.

\section{References}

1. Abend J.R., Low J.A., Imperiale M.J.: Inhibitory effect of gamma interferon on BK virus gene expression and replication. J Virol 2007, 81, 272-279, doi: 10.1128/JVI.01571-06.

2. Alhaji N.B., Amin J., Aliyu M.B., Mohammad B., Babalobi O.O., Wungak Y., Odetokun, I.A.: Economic impact assessment of footand-mouth disease burden and control in pastoral local dairy cattle production systems in Northern Nigeria: A cross-sectional survey. Prev Vet Med 2020, 177, 104974, doi: 10.1016/j.prevetmed. 2020.104974. 
3. Arzt J., Pacheco J.M., Stenfeldt C., Rodriguez L.L.: Pathogenesis of virulent and attenuated foot-and-mouth disease virus in cattle. Virol J 2017, 14, 89, doi: 10.1186/s12985-017-0758-9.

4. Biswal J.K., Ranjan R., Subramaniam S., Mohapatra J.K., Patidar S., Sharma M.K., Bertram M.R., Brito B.P., Rodriguez L.L., Pattnaik B., Arzt J.: Genetic and antigenic variation of foot-and-mouth disease virus during persistent infection in naturally infected cattle and Asian buffalo in India. PLoS ONE 2019, 14, e0214832, doi: 10.1371/journal.pone.0214832.

5. Brito B.P., Rodriguez L.L., Hammond J.M., Pinto J., Perez A.M: Review of the Global Distribution of Foot-and-Mouth Disease Virus from 2007 to 2014. Transbound Emerg Dis 2017, 64, 316-332, doi: 10.1111/tbed.12373.

6. Cottam E.M., Wadsworth J., Shaw A.E., Rowlands R.J., Goatley L., Maan S., Maan N.S., Mertens P.P., Ebert K., Li Y., Ryan E.D., Juleff N., Ferris N.P., Wilesmith J.W., Haydon D.T., King D.P., Paton D.J., Knowles N.J.: Transmission pathways of foot-andmouth disease virus in the United Kingdom in 2007. PLoS Pathog 2008, 4, e1000050, doi.org/10.1371/journal.ppat.1000050.

7. Doel T.: Chapter 5: Natural and Vaccine Induced Immunity to FMD. In: Foot-and-Mouth Disease Virus, edited by B.W.J. Mahy, Springer Nature, Cham, 2004, pp 103-131, doi: 10.1007/3-54027109-0_5.

8. Golde W.T., de los Santos T., Robinson L., Grubman M.J., Sevilla N., Summerfield A., Charleston B.: Evidence of activation and suppression during the early immune response to foot-and-mouth disease virus. Transbound Emerg Dis 2011, 58, 283-290, doi: 10.1111/j.1865-1682.2011.01223.x

9. Grubman M.J., Moraes M.P., Diaz-San Segundo F., Pena L., de los Santos T.: Evading the host immune response: how footand-mouth disease virus has become an effective pathogen. FEMS Immunol Med Microbiol 2008, 53, 8-17, doi: 10.1111/j.1574695X.2008.00409.x.

10. Haagmans B.L., Osterhaus A.D.M.E.: Chapter 36 - SARS. In: Vaccines for Biodefense and Emerging and Neglected Diseases, edited by A.D.T. Barrett, L.R. Stanberry. Academic Press Cambridge, MA, 2009, pp 671-683.

11. Janssens S., Beyaert R.: Role of Toll-Like Receptors in Pathogen Recognition. Clin Microbiol Rev 2003, 16, 637-646, doi: 10.1128/CMR.16.4.637-646.2003.

12. Kang S., Brown H.M., Hwang S.: Direct Antiviral Mechanisms of Interferon-Gamma. Immune Netw 2018, 18, e3, doi: 10.4110/ in.2018.18.e33.

13. Kitching R.P.: Chapter 6: Global epidemiology and prospects for control of foot-and-mouth disease. In: Foot-and-Mouth Disease Virus, edited by B.W.J. Mahy, Springer Nature, Cham, 2004, pp 133-148, doi.org/10.1007/3-540-27109-0 6 .

14. Kitching R.P.: Clinical variation in foot and mouth disease: Cattle. Rev Sci Tech Off Int Epiz 2003, 21, 499-504, doi: 10.20506/rst.21.3.1343.

15. Knight-Jones T.J.D., Rushton J.: The economic impacts of foot and mouth disease -what are they, how big are they and where do they occur? Prev Vet Med 2013, 112, 161-173, doi: 10.1016/j.prevetmed.2013.07.013.

16. Lindell D.M., Lane T.E., Lukacs N.W.: CxCL10/CxCR3mediated Responses Promote Immunity to Respiratory Syncytial Virus Infection by Augmenting Dendritic Cell and CD8+ T Cell Efficacy. Eur J Immunol 2008, 38, 2168-2179, doi.org/10.1002/eji.200838155.

17. Longjam N., Tayo T.: Antigenic variation of Foot and Mouth Disease Virus - An Overview. Vet World 2011, 4, 475-479, doi: 10.5455/vetworld.2011.475-479

18. Mahapatra M., Yuvaraj S., Madhanmohan M., Subramaniam S., Pattnaik B., Paton D.J., Srinivasan V.A., Parida S.: Antigenic and genetic comparison of foot-and-mouth disease virus serotype $\mathrm{O}$
Indian vaccine strain, $\mathrm{O} / \mathrm{IND} / \mathrm{R} 2 / 75$ against currently circulating viruses. Vaccine 2015, 33, 693-700, doi: 10.1016/j.vaccine. 2014.11.058.

19. Pacheco J.M., Smoliga G.R., O’Donnell V., Brito B.P., Stenfeldt C., Rodriguez L.L., Arzt J.: Persistent Foot-and-Mouth Disease Virus Infection in the Nasopharynx of Cattle; Tissue-Specific Distribution and Local Cytokine Expression. PLoS One, 2015, 10 , e0125698, doi: 10.1371/journal.pone.0125698.

20. Park J., Takeuchi A., Sharma S.: Characterization of a new isoform of the NFAT (nuclear factor of activated T cells) gene family member NFATc. J Biol Chem 1996, 271, 20914-20921, doi: $10.1074 / \mathrm{jbc} .271 .34 .20914$

21. Paton D.J., Gubbins S., King D.P.: Understanding the transmission of foot-and-mouth disease virus at different scales. Curr Opin Virol 2018, 28, 85-91, doi: 10.1016/j.coviro. 2017.11.013

22. Perry B.D., Rich K.M.: Poverty impacts of foot-and-mouth disease and the poverty reduction implications of its control. Vet Rec 2007, 160, 238-241, doi: 10.1136/vr.160.7.238.

23. Rao X., Huang X., Zhou Z., Lin X.: An improvement of the $2^{\wedge}$ (delta delta CT) method for quantitative real-time polymerase chain reaction data analysis. Biostat Bioinforma Biomath 2013, 3 , 71-85.

24. Razvi E.S., Welsh R.M.: Programmed cell death of T lymphocytes during acute viral infection: a mechanism for virus-induced immune deficiency. J Virol 1993, 67, 5754-5765, doi: 10.1128/JVI.67.10.5754-5765.1993.

25. Stenfeldt C., Heegaard P.M., Stockmarr A., Belsham G.J.: Modulation of cytokine mRNA expression in pharyngeal epithelial samples obtained from cattle infected with foot-andmouth disease virus. J Comp Pathol 2012, 146, 243-252, doi: 10.1016/j.jcpa.2011.06.005.

26. Schroder K., Hertzog P.J., RavasiT., Hume D.A.: Interferon-y: an overview of signals, mechanisms and functions. J Leukoc Biol 2004, 75, 163-189, doi: 10.1189/jlb.0603252.

27. Takeda K., Akira S.: Toll-like receptors. Curr Protoc Immunol 2015, 109, 14.12.1-14.12.10, doi: 10.1002/0471142735. im1412s 109 .

28. Thorley-Lawson D.A., Schooley R.T., Bhan A.K., Nadler L.M.: Epstein-Barr virus superinduces a new human B cell differentiation antigen (B-LAST 1) expressed on transformed lymphoblasts. Cell 1982, 30, 415-425, doi: 10.1016/00928674(82)90239-2.

29. Tissot C., Rebouissou C., Klein B., Mechti N.: Both human alpha/beta and gamma interferons upregulate the expression of CD48 cell surface molecules. J Interferon Cytokine Res 1997, 17, 17-26, doi: 10.1089/jir.1997.17.17.

30. World Organisation for Animal Health (OIE): Manual of Diagnostic Tests and Vaccines for Terrestrial Animals, 5th Edition. Paris, 2004, pp 15-17.

31. Van Wyk B., Snider M., Scruten E., van Drunen Littel-van den Hurk S., Scott Napper S.: Induction of functional interferon alpha and gamma responses during acute infection of cattle with noncytopathic bovine viral diarrhea virus. Vet Microbiol, 2016, 195, 104-114, doi: 10.1016/j.vetmic.2016.09.015.

32. Yokoyama S., Staunton D., Fisher R., Amiot M., Fortin J.J., Thorley-Lawson D.A.: Expression of the Blast-1 activation/adhesion molecule and its identification as CD48. J Immunol 1991,146, 2192-2200.

33. Zhang Z., Doel C., Bashiruddin J.B.: Interleukin-10 production at the early stage of infection with foot-and-mouth disease virus related to the likelihood of persistent infection in cattle. Vet Res 2015, 46, 132, doi: 10.1186/s13567-015-0276-y. 